\title{
TrpB2 Enzymes are O-Phospho-L-serine Dependent Tryptophan Synthases
}

\author{
Florian Busch, ${ }^{\ddagger}$ Chitra Rajendran, ${ }^{\ddagger}$ Olga Mayans, ${ }^{\dagger}$ Patrick Löffler, ${ }^{\ddagger}$ Rainer Merkl, ${ }^{\ddagger}$ \\ and Reinhard Sterner** \\ ${ }^{\ddagger}$ Institute of Biophysics and Physical Biochemistry, University of Regensburg, Universitätsstrasse 31, D-93053 Regensburg, Germany \\ ${ }^{\dagger}$ Institute of Integrative Biology, University of Liverpool, Crown Street, Liverpool L69 7ZB, United Kingdom
}

ABSTRACT: The rapid increase of the number of sequenced genomes asks for the functional annotation of the encoded enzymes. We used a combined computational-structural approach to determine the function of the $\operatorname{TrpB} 2$ subgroup of the tryptophan synthase $\beta$ chain/ $\beta$ chain-like TrpB1-TrpB2 family (IPR023026). The results showed that TrpB2 enzymes are O-phospho-L-serine dependent tryptophan synthases, whereas TrpB1 enzymes catalyze the L-serine dependent synthesis of tryptophan. We found a single residue being responsible for the different substrate specificities of TrpB1 and TrpB2 and confirmed this finding by mutagenesis studies and crystallographic analysis of a TrpB2 enzyme with bound O-phospho-Lserine.

$\mathrm{T}$ he tryptophan synthase $\beta$ chain/ $\beta$ chain-like family 1 (IPR023026) consists of two distinct groups, TrpB1 and TrpB2, which share a sequence identity of approximately $30 \%{ }^{1,2}$ Dimeric TrpB1 associates with two monomeric $\alpha$ subunits, TrpA, to the heterotetrameric $\alpha \beta \beta \alpha$ tryptophan synthase complex in which the two different kinds of subunits stimulate each other. ${ }^{3,4}$ The TrpA reaction generates glyceraldehyde-3-phosphate and indole. The latter is channeled to the active site of TrpB1 where it reacts with $\mathrm{L}$-serine to form tryptophan in a PLP-dependent condensation reaction. ${ }^{5-7}$ Both TrpB1 and TrpA are encoded within the trp operon.

The TrpB2 group can be further subdivided into $\operatorname{TrpB} 2 \mathrm{i}$, which is encoded within the trp operon, and $\operatorname{TrpB} 2 \mathrm{a}$ and TrpB2o, which are encoded outside the trp operon. ${ }^{1}$ It has been shown that the ssTrpB2i enzyme from Sulfolobus solfataricus forms with ssTrpA a transient, ligand-dependent tryptophan synthase complex having $\alpha \beta \beta$ stoichiometry. ${ }^{8,9}$ This finding indicates a functional equivalence of $\operatorname{TrpB} 2 \mathrm{i}$ and $\operatorname{TrpB} 1$ in vivo. In contrast, all $\operatorname{TrpB} 20$ and $\operatorname{TrpB} 2 \mathrm{a}$ enzymes characterized to date do not interact with $\operatorname{TrpA} .^{10,11}$ Nonetheless, in vitro they catalyze the PLP-dependent synthesis of L-tryptophan with a $K_{\mathrm{m}}$ for indole in the nanomolar range and a $K_{\mathrm{m}}$ for L-serine in the high millimolar range. However, the intracellular concentration of L-serine is supposed to be far below this $K_{\mathrm{m}}$ value, ${ }^{12}$ suggesting that $\operatorname{TrpB} 2$ uses a different substrate for tryptophan biosynthesis in vivo. For this reason, we have investigated the substrate specificity of TrpB2 based on structural considerations.

\section{MATERIALS AND METHODS}

Cloning. sttrpB1 was amplified from pBR322-sttrpAB (a gift from Dr. Ilme Schlichting) using the oligonucleotides AGC

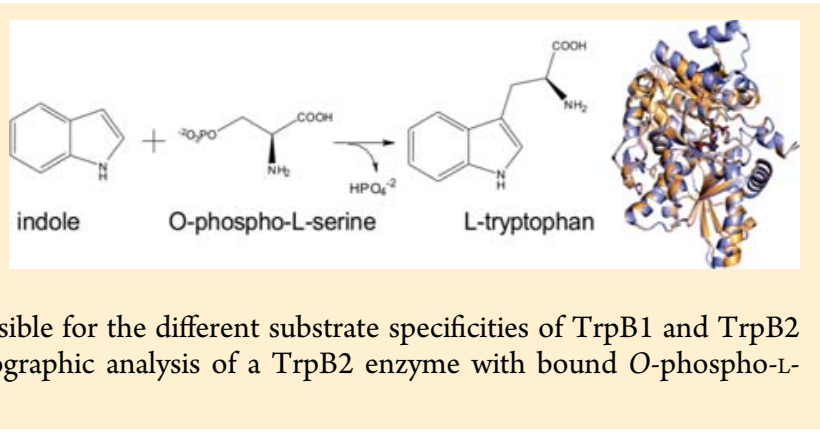

CAT ATG ACA ACA CTT CTC AAC CCC TAC and CTG GTG CAA GCT TGA TTT CCC CTC GCG CTT TCA GGA TATC and inserted into pET24a(+) at the NdeI/HindIII restriction sites. tmtrpB2o was amplified from pET21a(+)tmerpB2o ${ }^{10}$ using the oligonucleotides ACC GCA TAT GAG AAT TGT TGT GAA and CCC AGG AAT TCA GGC TTT CAC ACG TAC GCT GT and inserted into pET28a(+) at the $\mathrm{NdeI} /$ HindIII restriction sites. attrp $\mathrm{B} 2 \mathrm{o}$ was amplified from cDNA of Arabidopsis thaliana Col-0 using the oligonucleotides GCA GCT TTG AGA TCT ACT CA and TTA TGG GGC CAT TCG AGC TT. The amplification product was the template in a second round of PCR using the oligonucleotides CTA GCT TAA GAC ATA TGG CAG CTT TGA GA and TTA TGG GGC CAT GGA TCC TTA AAC AAC A. The final amplification product was inserted into the pET28a(+) expression vector at the $\mathrm{NdeI} / \mathrm{BamHI}$ restriction sites. sstrp B2a was amplified from pET28a(+)-sstrpB2a ${ }^{9}$ using the oligonucleotides TAA TAC GAC TCA CTA TAG GG and CCG CAA GCT TCT CCT TAA ATA ACA $\mathrm{C}$ and inserted into pET24a(+) at the NdeI/ HindIII restriction sites. sstrpB2aR337D was generated by QuikChange site-directed mutagenesis ${ }^{13}$ from pET28a(+)-sstrpB2a using the oligonucleotides TAT GCA GGT GGG CTA GAT TAT CAT GGA GTA GCC and GGC TAC TCC ATG ATA ATC TAG CCC ACC TGC ATA. The mutated gene was subcloned into $\operatorname{pET} 24 a(+)$ at the NdeI/HindIII restriction sites.

Gene Expression and Protein Purification. The proteins ssTrpB2i, ssTrpB2a, ssTrpB2a-R337D and tmTrpB2o were 
expressed with a His $_{6}$-tag and purified by a heat step and metal chelate affinity chromatography according to refs 9 and 10. For crystallization, ssTrpB2a was further purified by preparative gel filtration chromatography using an ÄKTA-purifier system with a HiLoad Superdex 75 PG column (120 mL, GE Healthcare).

For expression of stTrpB1, Escherichia coli T7 Express (NEB) was transformed with $\mathrm{pET} 24 \mathrm{a}(+)$-sttrpB. The cells were grown at $37^{\circ} \mathrm{C}$ in lysogenic broth (LB) with $50 \mu \mathrm{g} / \mathrm{mL}$ kanamycin to $\mathrm{OD}_{600}=0.5$. Protein expression was induced by addition of 0.5 $\mathrm{mM}$ IPTG. After growth overnight at $20{ }^{\circ} \mathrm{C}$, cells were harvested by centrifugation and disrupted by ultrasonication. The $\mathrm{His}_{6}$-tagged protein was purified by metal chelate affinity chromatography using an ÄKTA-purifier system with a HisTrap FF crude column ( $5 \mathrm{~mL}$, GE Healthcare). Proteins in $50 \mathrm{mM}$ Tris/ $\mathrm{HCl}, \mathrm{pH} 7.5$, and $150 \mathrm{mM} \mathrm{NaCl}$ were eluted by a linear gradient of imidazole $(10-500 \mathrm{mM})$ and dialyzed against 50 $\mathrm{mM}$ Tris/ $\mathrm{HCl}, \mathrm{pH} 7.5$.

For expression of atTrpB2o, E. coli DE3 (NEB) was transformed with pET28a(+)-attrpB2o. The cells were grown at $37^{\circ} \mathrm{C}$ in lysogenic broth (LB) with $50 \mu \mathrm{g} / \mathrm{mL}$ kanamycin to $\mathrm{OD}_{600}=0.5$. Protein expression was induced by addition of 0.5 $\mathrm{mM}$ IPTG. After growth overnight at $37{ }^{\circ} \mathrm{C}$, cells were harvested by centrifugation and disrupted by ultrasonication. The $\mathrm{His}_{6}$-tagged protein was purified by metal chelate affinity chromatography using an ÄKTA-purifier system with a HisTrap FF crude column ( $5 \mathrm{~mL}$, GE Healthcare). Proteins in $50 \mathrm{mM}$ potassium phosphate, $\mathrm{pH} 7.5$, and $300 \mathrm{mM} \mathrm{KCl}$ were eluted by a linear gradient of imidazole $(10-500 \mathrm{mM})$ and dialyzed against $50 \mathrm{mM}$ potassium phosphate, $\mathrm{pH}$ 7.5.

Crystallization and Structure Determination. Crystallization trials with $\operatorname{ssTrpB} 2$ a were performed with the vapor diffusion method in 24 well plates (Quiagen) at $18{ }^{\circ} \mathrm{C}$ based on previously established conditions (O. Mayans, unpublished data). Drops contained $1 \mu \mathrm{L}$ of ssTrpB2a $(12.5 \mathrm{mg} / \mathrm{mL})$ in 10 $\mathrm{mM}$ 4-(2-hydroxyethyl)-1-piperazineethanesulfonic acid (HEPES), $\mathrm{pH} 7.5$, and $25 \mathrm{mM} \mathrm{NaCl}$ and $1 \mu \mathrm{L}$ of reservoir solution. Equilibration was done against $500 \mu \mathrm{L}$ of reservoir solution. First crystals appeared after 1 week at $18{ }^{\circ} \mathrm{C}$ with $25 \%$ PEG-4000, 0.1 M Tris/HCl, $\mathrm{pH} 7.0$, and $100 \mathrm{mM} \mathrm{NaCl}$ as reservoir solution. Initially crystals appeared as clusters and were multicrystals. Seeding was tried to produce bigger single crystals with 20-25\% PEG-4000, 0.1 M Tris/HCl, $\mathrm{pH} 7.0 / 7.5 /$ $8.0 / 8.5$, and $100 \mathrm{mM} \mathrm{NaCl}$ as reservoir solution. After 1 month at $18{ }^{\circ} \mathrm{C}$, single crystals were collected, soaked with $200 \mathrm{mM} \mathrm{O}$ phospho-L-serine, and flash frozen in liquid nitrogen. Data of single crystals were collected at SLS beamline PXIII at $100 \mathrm{~K}$. Data were processed using $\mathrm{XDS},{ }^{14}$ and the data quality assessment was done using phenix.xtriage. ${ }^{15}$ Molecular replacement was performed with MOLREP within the CCP4i suite. $^{16}$ A homology model with ssTrpB2a (O. Mayans, unpublished data) was built with MODELER ${ }^{17}$ and served as a search model. Initial refinement was performed using REFMAC. ${ }^{18}$ The model was further improved in several refinement rounds using automated restrained refinement with the program PHENIX ${ }^{13}$ and interactive modeling with Coot. ${ }^{19}$ The final model was analyzed using the program MolProbity. ${ }^{20}$

Substrate Screening. Reaction mixtures $(100 \mu \mathrm{L})$ contained $100 \mathrm{mM}$ potassium phosphate buffer, $\mathrm{pH} 7.5,180$ $\mathrm{mM} \mathrm{KCl}, 40 \mu \mathrm{M}$ PLP, $500 \mu \mathrm{M}$ indole, $2 \mathrm{mM} \alpha$-amino acid, and $5 \mu \mathrm{M}$ enzyme. After incubation for $30 \mathrm{~min}$ at $25{ }^{\circ} \mathrm{C}(\mathrm{stTrpB} 1)$ or $60{ }^{\circ} \mathrm{C}$ (ssTrpB2i, ssTrpB2a, tmTrpB2o, atTrpB2o), reactions were quenched by the addition of $400 \mu \mathrm{L}$ of methanol. Conversion of indole was subsequently determined by reversed-phase HPLC (Agilent 1200). The separation was performed at $25{ }^{\circ} \mathrm{C}$ with a flow rate of $0.25 \mathrm{~mL} / \mathrm{min}$ on a reversed-phase Gemini-NX-C18 column $(3 \mathrm{~mm} \times 150 \mathrm{~mm}, 3$ $\mu \mathrm{m}$ particle size; Phenomenex) using $0.1 \%$ formic acid in water as buffer $\mathrm{A}$ and $0.1 \%$ formic acid in acetonitrile as buffer $\mathrm{B}$. The program was as follows: hold with $5 \% \mathrm{~B}$ for $3 \mathrm{~min}$, linear gradient 5-98\% B in $22.8 \mathrm{~min}$, hold with $100 \%$ B for $3.6 \mathrm{~min}$, recycle $100-5 \%$ B in $3.6 \mathrm{~min}$, and re-equilibrate with $5 \% \mathrm{~B}$ for $12 \mathrm{~min}$. The elution time was $19.7 \mathrm{~min}$ for indole.

Kinetic Measurements. Kinetics for the O-phospho-Lserine dependent synthesis of tryptophan were measured in 100 $\mathrm{mM}$ 3-[4-(2-hydroxyethyl)-1-piperazinyl]propanesulfonic acid (EPPS)/KOH, pH 7.5, $180 \mathrm{mM} \mathrm{KCl}$, and $40 \mu \mathrm{M}$ PLP with 100 $\mu \mathrm{M}$ indole and varying concentrations of $O$-phospho-L-serine at $80{ }^{\circ} \mathrm{C}(\operatorname{tm} \operatorname{TrpB} 2 \mathrm{o}), 60{ }^{\circ} \mathrm{C}$ (ssTrpB2a, ssTrpB2i), or $30{ }^{\circ} \mathrm{C}$ (atTrpB2o) by absorption spectroscopy using $\Delta \varepsilon_{280}$ (tryptophan - indole) $=1.89 \mathrm{mM}^{-1} \mathrm{~cm}^{-121}$ with a V650 spectrophotometer $(d=1 \mathrm{~cm}$; Jasco).

Fluorescence Titration. Binding of $\mathrm{L}$-serine and $\mathrm{O}$ phospho-L-serine to ssTrpB2a and ssTrpB2a-R337D was followed by fluorescence detection at $520 \mathrm{~nm}$ after excitation at $440 \mathrm{~nm}$ using a FP-6500 spectrofluorometer $(d=1 \mathrm{~cm}$; Jasco). The protein with a subunit concentration of $1 \mu \mathrm{M}$ was titrated with amino acid at $25{ }^{\circ} \mathrm{C}$ in $100 \mathrm{mM}$ potassium phosphate buffer, $\mathrm{pH}$ 7.5.

Isothermal Titration Calorimetry (ITC). ITC measurements were performed with a MicroCal iTC200 titration calorimeter (GE healthcare). To this purpose, the proteins were dialyzed against HBS-EP+, $60 \mathrm{mM}$ GP, $10 \mathrm{mM}$ O-phospho-Lserine, and $0.05 \%(\mathrm{w} / \mathrm{v})$ sodium azide. Titrations were conducted at $25{ }^{\circ} \mathrm{C}$ by injecting 24 aliquots of $1.6 \mu \mathrm{L}$ containing $188 \mu \mathrm{M}$ ssTrpA into $200 \mu \mathrm{L}$ containing ssTrpB2i at a subunit concentration of $21 \mu \mathrm{M}$. The thermodynamic dissociation constant $K_{\mathrm{d}}$ was calculated by a one site binding model implemented in the ITC Origin software.

Surface Plasmon Resonance (SPR). SPR measurements were perfomed on a Biacore X100 optical biosensor (GE healthcare). ssTrpA was covalently immobilized on flow cell 2 of a CM5 sensor chip using EDC/NHS chemistry. The ligand in $10 \mathrm{mM}$ sodium acetate buffer, $\mathrm{pH} 4.83$, was injected to obtain a final signal of 218.2 response units (RU). Interactions were measured at $25{ }^{\circ} \mathrm{C}$ at a flow rate of $30 \mu \mathrm{L} / \mathrm{min}$ using various concentrations of ssTrpB2i as analyte in HBS-EP+, 60 $\mathrm{mM} \mathrm{GP}$, and $0.05 \%(\mathrm{w} / \mathrm{v})$ sodium azide in the presence of 10 $\mathrm{mM} O$-phospho-L-serine, $1 \mathrm{M}$ L-serine or $1 \mathrm{M}$ glycine. The binding surface was regenerated after each injection with HBS$\mathrm{EP}+. K_{\mathrm{d}}$ values were determined by using a steady-state binding model.

\section{RESULTS AND DISCUSSION}

The detailed reaction mechanism of the TrpB2 enzymes is unknown, and no crystal structure has been available for this group so far. In contrast, the structure-function relationship of the TrpB1 group is well understood, mainly based on studies of stTrpB1 from Salmonella typhimurium. Here, catalysis involves the formation of an external aldimine between the cofactor PLP and the substrate $\mathrm{L}$-serine. We analyzed the coordination of this intermediate in stTrpB1 and compared it with a most plausible coordination in a homology model generated for ssTrpB2a from S. solfataricus (Figure 1).

The cofactor PLP is bound in the same position, and the nitrogen of the pyridinium ring is coordinated by equivalent serine residues in $s t \operatorname{TrpB} 1$ and $s s \operatorname{TrpB} 2 \mathrm{a}$, which indicates that 


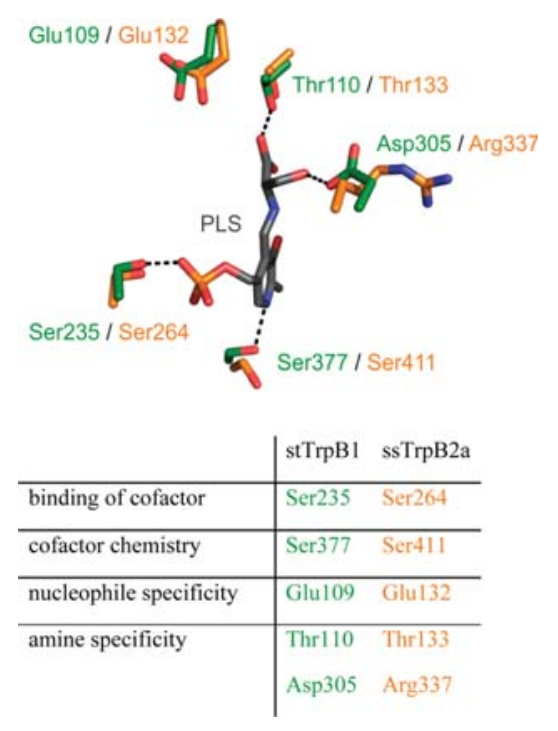

Figure 1. Superposition of the active sites of stTrpB1 and ssTrpB2a. Active site residues of stTrpB1 (PDB ID 1KFJ) are shown as green sticks and the aldimine between PLP and L-serine (PLS) is shown as gray sticks. Hydrogen bonds between side chains and PLS are indicated by black dashes. ssTrpB2a was modeled by means of Yasara Structure (www.yasara.org) using $1 \mathrm{KFJ}$ as template, and superimposed active site residues are shown as yellow sticks. The role of the depicted residues in catalysis is given according to experimental data for stTrpB1. ${ }^{3,39-43}$

both enzyme groups use the same cofactor chemistry. The specificity for using indole as nucleophile is determined by a glutamate residue, which is strictly conserved in all $\operatorname{TrpB}$ enzymes. Moreover, both TrpB subfamilies utilize a threonine residue to coordinate the carboxyl moiety of bound L-serine. Whereas the hydroxyl group of L-serine is coordinated by an aspartate in TrpB1, all TrpB2 enzymes have an arginine at that position (Figure S1, Supporting Information). This difference prompted us to test stTrpB1 and various TrpB2 enzymes (ssTrpB2i, ssTrpB2a, tmTrpB2o from Thermotoga maritima, and at $\operatorname{TrpB} 20$ from Arabidopsis thaliana) for their ability to catalyze the conversion of indole with $\alpha$-amino acids other than L-serine (L-threonine, D-threonine, DL-phenylserine, O-phospho-L-threonine, D-serine, L-cysteine, D-cysteine, DL-diaminopropionate, $O$-acetyl-L-serine, $O$-phospho-L-serine, and $O$ phospho-D-serine). The results are shown in Table S1, Supporting Information.

Whereas TrpB1 preferentially uses L-serine as substrate, all studied TrpB2 enzymes have a pronounced preference for $O$ phospho-L-serine. In order to further analyze this finding, we determined the steady-state kinetic parameters of the TrpB2 enzymes for the $O$-phospho-L-serine dependent synthesis of tryptophan and compared them with the parameters of the Lserine dependent synthesis (Table 1).

The $K_{\mathrm{m}}^{\mathrm{O}-\text {-phospho-L-serine }}$ values of all TrpB2 lie within range of $10-1000 \mu \mathrm{M}$, which is found for $\sim 60 \%$ of enzymes in the KEGG database. ${ }^{22}$ Since these values are much lower than their $K_{\mathrm{m}}^{\mathrm{L}-\mathrm{serine}}$ values and the corresponding turnover numbers $k_{\text {cat }}$ are similar, the catalytic efficiencies $k_{\text {cat }} / K_{\mathrm{m}}^{O-p h o s p h o-L-s e r i n e ~}$ are higher by about 3-4 orders of magnitude than the catalytic efficiencies $k_{\text {cat }} / K_{\mathrm{m}}^{\mathrm{L}-\mathrm{serine}}$. We conclude from these results that TrpB2 enzymes catalyze the reaction of indole with $O$-phospho-Lserine in vivo. This is a new role for $O$-phospho-L-serine, which
Table 1. Steady-State Kinetic Parameters of TrpB2 Enzymes with $\mathrm{L}$-Serine and $O$-Phospho-L-serine as Substrates ${ }^{a}$

\begin{tabular}{llcl} 
& $k_{\text {cat }}\left(\mathrm{s}^{-1}\right)$ & $K_{\mathrm{m}}(\mathrm{mM})$ & $k_{\text {cat }} / K_{\mathrm{m}}\left(\mathrm{M}^{-1} \mathrm{~s}^{-1}\right)$ \\
tmTrpB2o & \multicolumn{4}{c}{ L-Serine } & Dependent Reaction \\
ssTrpB2a & 0.44 & 50.2 & $8.7 \times 10^{0}$ \\
ssTrpB2i & 0.032 & 151 & $2.1 \times 10^{-1}$ \\
atTrpB2o & 0.20 & 35 & $5.7 \times 10^{0}$ \\
& 0.016 & 35 & $4.5 \times 10^{-1}$ \\
tmTrpB2o & 0.414 & 0.316 & $1.3 \times 10^{3}$ \\
ssTrpB2a & 0.015 & 0.014 & $1.1 \times 10^{3}$ \\
ssTrpB2i & 0.300 & 0.015 & $2.0 \times 10^{4}$ \\
atTrpB2o & 0.015 & 0.010 & $1.5 \times 10^{3}$ \\
a & & &
\end{tabular}

${ }^{a}$ Parameters for the L-serine dependent reaction at $80{ }^{\circ} \mathrm{C}(\operatorname{tmTrpB} 2 \mathrm{o})$, $60{ }^{\circ} \mathrm{C}$ (ssTrpB2a, ssTrpB2i), and $30^{\circ} \mathrm{C}$ (atTrpB2o) are according to refs 9,10 , and 44. Conditions for the $O$-phospho-L-serine dependent tryptophan synthase reaction: $100 \mathrm{mM}$ EPPS/KOH, $\mathrm{pH} 7.5,180 \mathrm{mM}$ $\mathrm{KCl}, 40 \mu \mathrm{M}$ PLP, $100 \mu \mathrm{M}$ indole. The measurements were made in duplicate with a deviation of less than $30 \%$ for the determined constants.

has been known up to now only as an intermediate of L-serine, L-cysteine, and L-cystathionine biosynthesis. ${ }^{23,24}$

We subsequently solved the structure of the ssTrpB2a dimer with external aldimine between PLP and $O$-phospho-L-serine at one subunit and internal aldimine between PLP and Lys111 at the other subunit (Figure 2; Table S2, Supporting Information). The binding of $O$-phospho-L-serine to the active site of ssTrpB2a leads to a conformational change from an open to a closed state (Figure 2A,B). Such a conformational change upon substrate binding was also observed for $\operatorname{st}^{\operatorname{TrpB} 1.25,26}$ As predicted by homology modeling (Figure 1), the cofactor within the active site in the crystal structure is coordinated with hydrogen bonding interactions to Thr133, Ser264, and Ser411 (Figure 2C). Binding of $O$-phospho-L-serine leads to a reorientation of Thr133 and Arg337, which facilitates the coordination of the carbonyl and the phosphate groups of PLP. The replacement of Arg337 by aspartate using site-directed mutagenesis results in the inversion of substrate binding from $O$-phospho-L-serine to $\mathrm{L}$-serine as indicated by fluorescence titration experiments (Table 2).

The closest homologue to tryptophan synthases TrpB1/ TrpB2 is the family of cysteine synthases CysM/CysK, which shares the same fold and catalyzes a $\beta$-replacement reaction via the same $\alpha$-aminoacryl intermediate. ${ }^{27}$ Recent investigations revealed that some cysteine synthases use $O$-phospho-L-serine instead of $O$-acetyl-L-serine as substrate. ${ }^{24,28-30}$ Like in TrpB2 enzymes, the coordination of the phosphate leaving group seems to be accomplished by an arginine residue. ${ }^{30}$

It has been shown that saturating concentrations of the ssTrpA ligand glycerol-3-phosphate (GP) and the ssTrpB2i ligand $\mathrm{L}$-serine induce the formation of a transient $\alpha \beta \beta$ complex. ${ }^{8}$ We tested the consequences of replacing L-serine by $O$-phospho-L-serine or glycine for complex formation between ssTrpB2i and ssTrpA. Surface plasmon resonance and isothermal titration calorimetry showed that the affinity between ssTrpB2i and ssTrpA was identical, independent of the used ssTrpB2i ligand (Table S3, Supporting Information). These results indicate that the ssTrpA-ssTrpB2i complex is formed with equal propensity, no matter whether the $\beta$ substituent of the ssTrpB2i ligand is $-\mathrm{H},-\mathrm{CH}_{2} \mathrm{OH}$, or $-\mathrm{CH}_{2} \mathrm{OPO}_{3}{ }^{2-}$. 

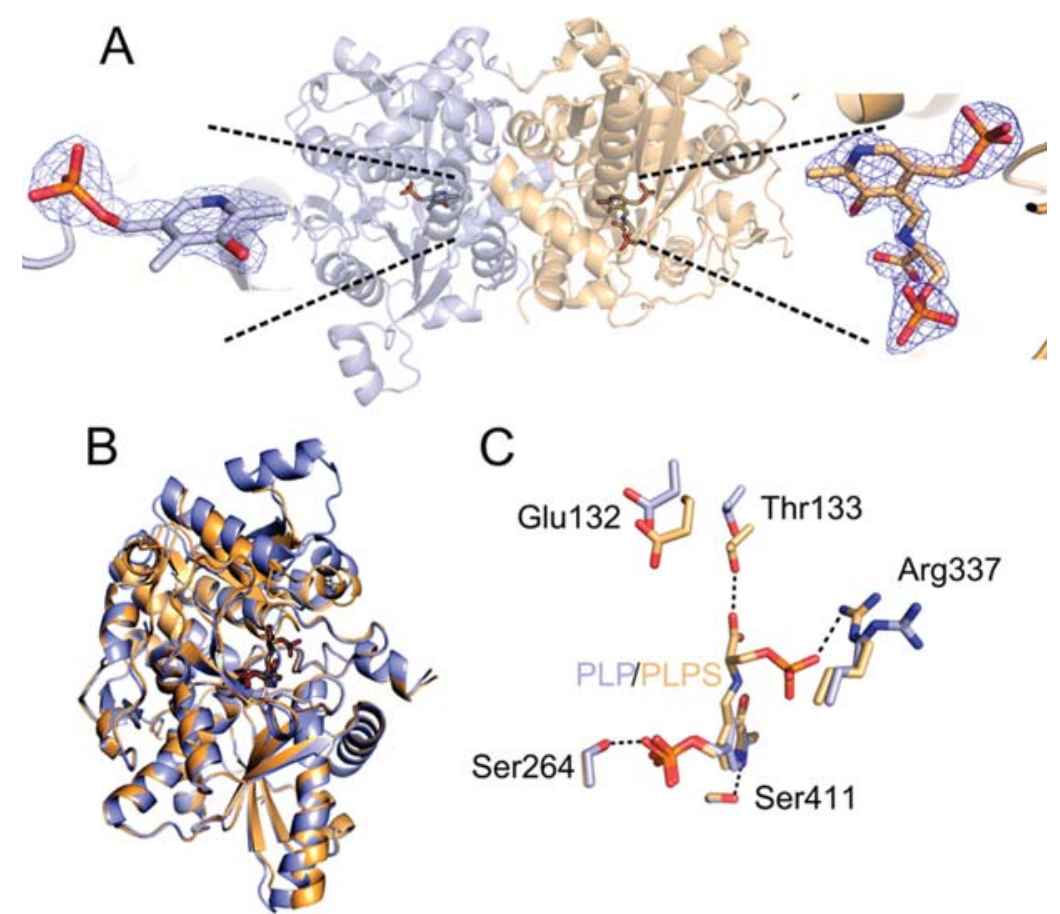

Figure 2. (A) Crystal structure of the ssTrpB2a homodimer (PDB ID 4QYS). The subunit with bound PLP is colored blue; the subunit with the external aldimine between PLP and O-phospho-L-serine (PLPS) is colored yellow. Both subunits are shown as ribbon diagrams, and the ligands are shown as sticks. Electron densities for PLP (left panel) and PLPS (right panel) are indicated by a refined $2 F_{\mathrm{o}}-F_{\mathrm{c}}$ map, contoured at $0.586 \mathrm{e} / \AA^{3}$ $(2.01 \mathrm{rmsd})$. (B) Superposition of open and closed conformations of ssTrpB2a. The PLP-bound subunit with open conformation and the PLPSbound subunit with closed conformation are superimposed. (C) View of the active sites of ssTrpB2a with bound PLP and PLPS. Side chains are shown as balls and sticks, and H-bonds are indicated by black dashes.

Table 2. Binding of L-Serine and $O$-Phospho-L-serine to ssTrpB2a and ssTrpB2a-R337D as Analyzed by Fluorescence Titration $^{a}$

$\begin{array}{lcc} & K_{\mathrm{d}}^{\mathrm{L}-\text { serine }}(\mathrm{mM}) & K_{\mathrm{d}}^{\text {O-phospho-L-serine }}(\mathrm{mM}) \\ \text { ssTrpB2a wt } & b & 0.08 \\ \text { ssTrpB2a-R337D } & 4 & b\end{array}$

${ }^{a}$ Reaction conditions: $100 \mathrm{mM}$ potassium phosphate buffer, $\mathrm{pH}$ 7.5. The determined $K_{\mathrm{d}}$ values are shown. The measurements were made in duplicate with a deviation of less than $20 \%$ for the determined constants. ${ }^{b}$ Undetectably low affinity binding.

The ability of $\operatorname{TrpB} 2$ to synthesize tryptophan in vivo was recently analyzed using the hyperthermophile Thermococcus kodakarensis, which can be genetically manipulated. ${ }^{31,32} T$. kodakarensis has a tkTrpB1 enzyme, which is part of the $\alpha \beta \beta \alpha$ tryptophan synthase complex, and a tkTrpB2o enzyme that does not interact with tkTrpA. A T. kodakarensis $\Delta \operatorname{trp} B 1$ strain was created, which lacks TrpB1 activity and has an insufficient TrpA activity due to the missing activation by the binding partner. However, $\Delta \operatorname{trp} \mathrm{B} 1$ thrived equally well as the wild-type strain in minimal medium supplemented with indole. ${ }^{11}$ Also, the transcription of some $\operatorname{tr} \mathrm{B} 2$ genes was shown to be similarly regulated as $\operatorname{trp} \mathrm{B} 1 .^{11,33}$ These findings suggest that $\operatorname{TrpB} 2$ enzymes act as tryptophan synthases in vivo and primordially evolved for the catalysis of the last step in tryptophan biosynthesis. Interestingly, several organisms harboring TrpB2i or TrpB1 enzymes still possess TrpB2o or TrpB2a proteins. The presence of two TrpB2 enzymes seems to be a minor advantage as indicated by the uneven distribution of TrpB2a in closely related Sulfolobales (TrpB2a is present in $S$. solfataricus and $S$. tokodaii but absent in S. acidocaldarius). In contrast, differences of $\operatorname{TrpB} 1$ and $\operatorname{TrpB} 2$ in substrate specificity and affinity may provide a selective advantage by helping to regulate the intracellular concentration of free indole. The specific reason is unclear; however it is known that indole is involved in various biological processes like biofilm formation, ${ }^{34}$ cell cycle control, ${ }^{35,36}$ and regulation of gene expression. $^{37,38}$

\section{ASSOCIATED CONTENT}

S Supporting Information

Conservation of substrate specifying residue, use of $\alpha$-amino acids by $\operatorname{TrpB}$ enzymes, data collection and refinement statistics, dependence of complex formation between ssTrpA and ssTrpB2i on the $\operatorname{TrpB} 2 \mathrm{i}$ ligand, and supporting references. This material is available free of charge via the Internet at http://pubs.acs.org.

\section{Accession Codes}

The X-ray coordinates have been deposited in the Protein Data Bank as entry 4QYS.

\section{AUTHOR INFORMATION}

\section{Corresponding Author}

*R.S. Phone: +49-941-943 3015. Fax: +49-941-943 2813. Email: Reinhard.Sterner@ur.de.

\section{Notes}

The authors declare no competing financial interest. 


\section{ACKNOWLEDGMENTS}

We thank Hermine Reisner and Sonja Fuchs for technical assistance and Vanya Uzunova from GE healthcare for making available the MicroCal iTC200 titration calorimeter.

\section{ABBREVIATIONS}

at, Arabidopsis thaliana; PLP, pyridoxal-5'-phosphate; PLS, aldimine between PLP and L-serine; PLPS, aldimine between PLP and O-phospho-L-serine; ss, Sulfolobus solfataricus; st, Salmonella typhimurium; tk, Thermococcus kodakarensis; tm, Thermotoga maritima

\section{REFERENCES}

(1) Merkl, R. (2007) Modelling the evolution of the archeal tryptophan synthase. BMC Evol. Biol. 7, 59.

(2) Xie, G., Forst, C., Bonner, C., and Jensen, R. A. (2002) Significance of two distinct types of tryptophan synthase $\beta$ chain in bacteria, archaea and higher plants. Genome Biol. 3, No. RESEARCH0004.

(3) Hyde, C. C., Ahmed, S. A., Padlan, E. A., Miles, E. W., and Davies, D. R. (1988) Three-dimensional structure of the tryptophan synthase $\alpha_{2} \beta_{2}$ multienzyme complex from Salmonella typhimurium. J. Biol. Chem. 263, 17857-17871.

(4) Kirschner, K., Lane, A. N., and Strasser, A. W. (1991) Reciprocal communication between the lyase and synthase active sites of the tryptophan synthase bienzyme complex. Biochemistry 30, 472-478.

(5) Huang, X., Holden, H. M., and Raushel, F. M. (2001) Channeling of substrates and intermediates in enzyme-catalyzed reactions. Аnпи. Rev. Biochem. 70, 149-180.

(6) Miles, E. W., Rhee, S., and Davies, D. R. (1999) The molecular basis of substrate channeling. J. Biol. Chem. 274, 12193-12196.

(7) Raushel, F. M., Thoden, J. B., and Holden, H. M. (2003) Enzymes with molecular tunnels. Acc. Chem. Res. 36, 539-548.

(8) Ehrmann, A., Richter, K., Busch, F., Reimann, J., Albers, S. V., and Sterner, R. (2010) Ligand-induced formation of a transient tryptophan synthase complex with $\alpha \beta \beta$ subunit stoichiometry. Biochemistry 49, $10842-10853$.

(9) Leopoldseder, S., Hettwer, S., and Sterner, R. (2006) Evolution of multi-enzyme complexes: The case of tryptophan synthase. Biochemistry 45, 14111-14119.

(10) Hettwer, S., and Sterner, R. (2002) A novel tryptophan synthase $\beta$-subunit from the hyperthermophile Thermotoga maritima. Quaternary structure, steady-state kinetics, and putative physiological role. J. Biol. Chem. 277, 8194-8201.

(11) Hiyama, T., Sato, T., Imanaka, T., and Atomi, H. (2014) The tryptophan synthase $\beta$-subunit paralogs $\operatorname{TrpB} 1$ and TrpB2 in Thermococcus kodakarensis are both involved in tryptophan biosynthesis and indole salvage. FEBS J. 281, 3113-3125.

(12) Bennett, B. D., Kimball, E. H., Gao, M., Osterhout, R., Van Dien, S. J., and Rabinowitz, J. D. (2009) Absolute metabolite concentrations and implied enzyme active site occupancy in Escherichia coli. Nat. Chem. Biol. 5, 593-599.

(13) Wang, W., and Malcolm, B. A. (1999) Two-stage PCR protocol allowing introduction of multiple mutations, deletions and insertions using QuikChange Site-Directed Mutagenesis. BioTechniques 26, 680682.

(14) Kabsch, W. (2010) Xds. Acta Crystallogr., Sect. D: Biol. Crystallogr. 66, 125-132.

(15) Adams, P. D., Grosse-Kunstleve, R. W., Hung, L. W., Ioerger, T. R., McCoy, A. J., Moriarty, N. W., Read, R. J., Sacchettini, J. C., Sauter, N. K., and Terwilliger, T. C. (2002) PHENIX: Building new software for automated crystallographic structure determination. Acta Crystallogr., Sect. D: Biol. Crystallogr. 58, 1948-1954.

(16) Potterton, L., McNicholas, S., Krissinel, E., Gruber, J., Cowtan, K., Emsley, P., Murshudov, G. N., Cohen, S., Perrakis, A., and Noble, M. (2004) Developments in the CCP4 molecular-graphics project. Acta Crystallogr., Sect. D: Biol. Crystallogr. 60, 2288-2294.
(17) Sali, A., and Blundell, T. L. (1993) Comparative protein modelling by satisfaction of spatial restraints. J. Mol. Biol. 234, 779815.

(18) Murshudov, G. N., Vagin, A. A., and Dodson, E. J. (1997) Refinement of macromolecular structures by the maximum-likelihood method. Acta Crystallogr., Sect. D: Biol. Crystallogr. 53, 240-255.

(19) Emsley, P., and Cowtan, K. (2004) Coot: Model-building tools for molecular graphics. Acta Crystallogr., Sect. D: Biol. Crystallogr. 60, $2126-2132$.

(20) Davis, I. W., Leaver-Fay, A., Chen, V. B., Block, J. N., Kapral, G. J., Wang, X., Murray, L. W., Arendall, W. B., 3rd, Snoeyink, J., Richardson, J. S., and Richardson, D. C. (2007) MolProbity: all-atom contacts and structure validation for proteins and nucleic acids. Nucleic Acids Res. 35, W375-383.

(21) Faeder, E. J., and Hammes, G. G. (1970) Kinetic studies of tryptophan synthetase. Interaction of substrates with the B subunit. Biochemistry 9, 4043-4049.

(22) Bar-Even, A., Noor, E., Savir, Y., Liebermeister, W., Davidi, D., Tawfik, D. S., and Milo, R. (2011) The moderately efficient enzyme: Evolutionary and physicochemical trends shaping enzyme parameters. Biochemistry 50, 4402-4410.

(23) Helgadottir, S., Rosas-Sandoval, G., Soll, D., and Graham, D. E. (2007) Biosynthesis of phosphoserine in the Methanococcales. J. Bacteriol. 189, 575-582.

(24) Mino, K., and Ishikawa, K. (2003) A novel O-phospho-L-serine sulfhydrylation reaction catalyzed by O-acetylserine sulfhydrylase from Aeropyrum pernix K1. FEBS Lett. 551, 133-138.

(25) Dunn, M. F., Aguilar, V., Brzovic, P., Drewe, W. F., Jr., Houben, K. F., Leja, C. A., and Roy, M. (1990) The tryptophan synthase bienzyme complex transfers indole between the $\alpha$ - and $\beta$-sites via a 25-30 Å long tunnel. Biochemistry 29, 8598-8607.

(26) Dunn, M. F., Niks, D., Ngo, H., Barends, T. R., and Schlichting, I. (2008) Tryptophan synthase: The workings of a channeling nanomachine. Trends Biochem. Sci. 33, 254-264.

(27) Burkhard, P., Tai, C. H., Ristroph, C. M., Cook, P. F., and Jansonius, J. N. (1999) Ligand binding induces a large conformational change in O-acetylserine sulfhydrylase from Salmonella typhimurium. J. Mol. Biol. 291, 941-953.

(28) Agren, D., Schnell, R., Oehlmann, W., Singh, M., and Schneider, G. (2008) Cysteine synthase (CysM) of Mycobacterium tuberculosis is an O-phosphoserine sulfhydrylase: Evidence for an alternative cysteine biosynthesis pathway in mycobacteria. J. Biol. Chem. 283, 3156731574.

(29) Nakamura, T., Kawai, Y., Kunimoto, K., Iwasaki, Y., Nishii, K., Kataoka, M., and Ishikawa, K. (2012) Structural analysis of the substrate recognition mechanism in O-phosphoserine sulfhydrylase from the hyperthermophilic archaeon Aeropyrum pernix K1. J. Mol. Biol. 422, 33-44.

(30) Oda, Y., Mino, K., Ishikawa, K., and Ataka, M. (2005) Threedimensional structure of a new enzyme, O-phosphoserine sulfhydrylase, involved in L-cysteine biosynthesis by a hyperthermophilic archaeon, Aeropyrum pernix K1, at 2.0A resolution. J. Mol. Biol. 351, 334-344.

(31) Sato, T., Fukui, T., Atomi, H., and Imanaka, T. (2003) Targeted gene disruption by homologous recombination in the hyperthermophilic archaeon Thermococcus kodakaraensis KOD1. J. Bacteriol. $185,210-220$

(32) Sato, T., Fukui, T., Atomi, H., and Imanaka, T. (2005) Improved and versatile transformation system allowing multiple genetic manipulations of the hyperthermophilic archaeon Thermococcus kodakaraensis. Appl. Environ. Microbiol. 71, 3889-3899.

(33) Karr, E. A., Sandman, K., Lurz, R., and Reeve, J. N. (2008) TrpY regulation of trpB2 transcription in Methanothermobacter thermautotrophicus. J. Bacteriol. 190, 2637-2641.

(34) Hu, M., Zhang, C., Mu, Y., Shen, Q., and Feng, Y. (2010) Indole affects biofilm formation in bacteria. Indian J. Microbiol. 50, 362-368.

(35) Chant, E. L., and Summers, D. K. (2007) Indole signalling contributes to the stable maintenance of Escherichia coli multicopy plasmids. Mol. Microbiol. 63, 35-43. 
(36) Chattoraj, D. K. (2007) Tryptophanase in sRNA control of the Escherichia coli cell cycle. Mol. Microbiol. 63, 1-3.

(37) Mueller, R. S., Beyhan, S., Saini, S. G., Yildiz, F. H., and Bartlett, D. H. (2009) Indole acts as an extracellular cue regulating gene expression in Vibrio cholerae. J. Bacteriol. 191, 3504-3516.

(38) Wang, D., Ding, X., and Rather, P. N. (2001) Indole can act as an extracellular signal in Escherichia coli. J. Bacteriol. 183, 4210-4216.

(39) Brzovic, P. S., Ngo, K., and Dunn, M. F. (1992) Allosteric interactions coordinate catalytic activity between successive metabolic enzymes in the tryptophan synthase bienzyme complex. Biochemistry 31, 3831-3839.

(40) Ferrari, D., Niks, D., Yang, L. H., Miles, E. W., and Dunn, M. F. (2003) Allosteric communication in the tryptophan synthase bienzyme complex: roles of the $\beta$-subunit aspartate 305-arginine 141 salt bridge. Biochemistry 42, 7807-7818.

(41) Ferrari, D., Yang, L. H., Miles, E. W., and Dunn, M. F. (2001) $\beta \mathrm{D} 305 \mathrm{~A}$ mutant of tryptophan synthase shows strongly perturbed allosteric regulation and substrate specificity. Biochemistry 40, 74217432.

(42) Jhee, K. H., McPhie, P., Ro, H. S., and Miles, E. W. (1998) Tryptophan synthase mutations that alter cofactor chemistry lead to mechanism-based inactivation. Biochemistry 37, 14591-14604.

(43) Rhee, S., Parris, K. D., Hyde, C. C., Ahmed, S. A., Miles, E. W., and Davies, D. R. (1997) Crystal structures of a mutant ( $\beta \mathrm{K} 87 \mathrm{~T})$ tryptophan synthase $\alpha_{2} \beta_{2}$ complex with ligands bound to the active sites of the $\alpha$ - and $\beta$-subunits reveal ligand-induced conformational changes. Biochemistry 36, 7664-7680.

(44) Yin, R., Frey, M., Gierl, A., and Glawischnig, E. (2010) Plants contain two distinct classes of functional tryptophan synthase beta proteins. Phytochemistry 71, 1667-1672. 